\title{
Improved right ventricular outflow tract function in patients with Tetralogy of Fallot after infundibular sparing compared to transventricular repair
}

\author{
Shiraz Maskatia ${ }^{1 *}$, Mary K Olive ${ }^{1}$, Nicholas A Dodd ${ }^{2}$, Rajesh Krishnamurthy ${ }^{2}$, Charles D Fraser ${ }^{3}$, \\ Emmett D McKenzie ${ }^{3}$, James M Hammel ${ }^{4}$, Shelby Kutty ${ }^{5}$
}

From 18th Annual SCMR Scientific Sessions

Nice, France. 4-7 February 2015

\section{Background}

The right ventricular infundibular sparing approach (RVIS) to repair tetralogy of Fallot (TOF) avoids a ventricular incision used in the transventricular (TV) approach. Recent data has demonstrated better global right ventricular systolic function in patients who underwent RVIS compared to those who had a TV repair, however the impact of surgical strategy on RV infundibular size and function is not specifically known. We hypothesized that patients repaired with the RVIS approach have improved RV outflow tract ejection fraction (RVOTEF) and have lower RV outflow tract volumes as assessed by cardiac magnetic resonance (CMR) compared with those repaired with the TV approach.

\section{Methods}

A cohort of 30 TOF patients with RVIS repair and follow up CMR was identified, and compared with 30 agematched TOF patients who had TV repair at a collaborating institution. Minor heterogeneity existed in the methods used to relieve RVOT obstruction, as efforts were made to spare the pulmonary valve in both groups. The primary outcome was RVOTEF. Secondary endpoints included end diastolic and end systolic volumes (RVOTEDV and RVOTESV) indexed to body surface area. The RVOT was contoured from the base of the septal band to the pulmonary valve superiorly at end diastole (Figure 1a) and at end systole (Figure 1b) on steady-state free-precession short-axis cine stack. An

${ }^{1}$ Pediatric Cardiology, Baylor College of Medicine, Houston, TX, USA Full list of author information is available at the end of the article experienced blinded observer made all RVOT measurements on an independent workstation (CMR42, Circle CVI Inc, Calgary, Canada). Chi-Square, Student's t, Pearson correlation and Mann-Whitney tests were used as appropriate.

\section{Results}

Sixty patients were included in the analysis; 30 underwent RVIS repair at median age of 10.8 months (IQR: 6.3-29.3) and 30 underwent TV repair at median age of 4.2 months (IQR: 2.2-7.0), $(\mathrm{p}<0.01)$. No patient in the TV group had an initial palliation with a systemic to pulmonary arterial shunt compared to 4 (13\%) in the RVIS group $(\mathrm{p}<0.01)$. The median age at CMR was 8.4 years (IQR: $5.6-13.8$ ) in the RVIS group and 7.9 years (IQR: 3.4-12.0) in the TV group ( $\mathrm{p}=0.40)$. Compared to the TV group, the RVIS group had higher RVOTEF (51 $\pm 8 \%$ vs $42 \pm 12 \%, \mathrm{p}<0.01)$, lower RVOTEDV $(25 \pm 8$ $\mathrm{cc} / \mathrm{m}^{2}$ vs $\left.32 \pm 12 \mathrm{cc} / \mathrm{m}^{2}, \mathrm{p}=0.02\right)$, and lower RVOTESV $\left(12 \pm 4 \mathrm{cc} / \mathrm{m}^{2}\right.$ vs $\left.18 \pm 8 \mathrm{cc} / \mathrm{m}^{2}, \mathrm{p}<0.01\right)$. There was a modest correlation between RVOTEF and global RVEF $(\mathrm{R}=0.42, \mathrm{p}<0.01)$.

\section{Conclusions}

Patients who underwent RVIS repair for TOF appeared to have less dilation and improved systolic function of the RVOT compared to a matched cohort repaired using the TV approach. Favorable alteration in infundibular characteristics may explain the improved RV systolic function seen with the RVIS approach. Further work is needed to determine whether these differences are predictive of clinical outcomes. 


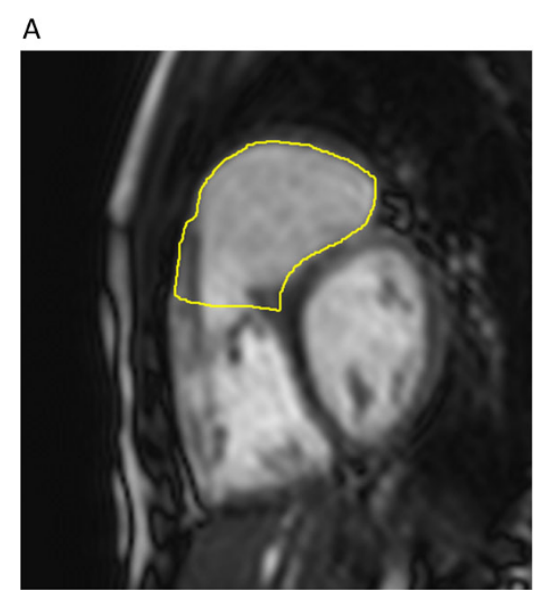

B

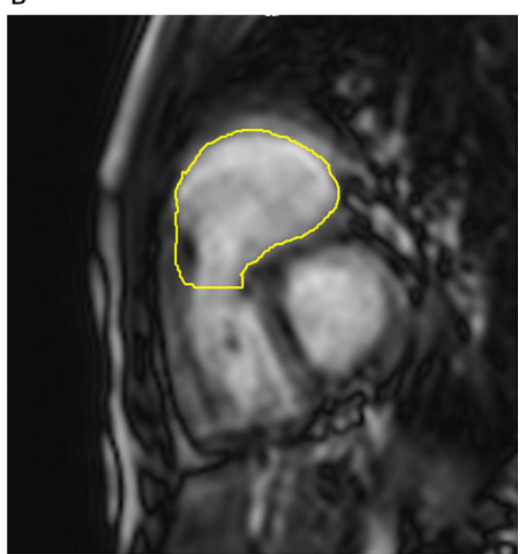

Figure 1 Characteristic RVOT contours at end diastole (a) and end systole (b)

\section{Funding}

None.

\section{Authors' details}

${ }^{1}$ Pediatric Cardiology, Baylor College of Medicine, Houston, TX, USA.

${ }^{2}$ Pediatric Radiology, Baylor College of Medicine, Houston, TX, USA.

${ }^{3}$ Congenital Heart Surgery, Baylor College of Medicine, Houston, TX, USA.

${ }^{4}$ Congenital Heart Surgery, University of Nebraska, Omaha, NE, USA.

${ }^{5}$ Pediatric Cardiology, University of Nebraska, Omaha, NE, USA.

Published: 3 February 2015

doi:10.1186/1532-429X-17-S1-Q81

Cite this article as: Maskatia et al: Improved right ventricular outflow

tract function in patients with Tetralogy of Fallot after infundibular

sparing compared to transventricular repair. Journal of Cardiovascular

Magnetic Resonance 2015 17(Suppl 1):Q81.

\section{Submit your next manuscript to BioMed Central} and take full advantage of:

- Convenient online submission

- Thorough peer review

- No space constraints or color figure charges

- Immediate publication on acceptance

- Inclusion in PubMed, CAS, Scopus and Google Scholar

- Research which is freely available for redistribution

Submit your manuscript at www.biomedcentral.com/submit
Biomed Central 